\title{
25 Research Square \\ Predicting climate effects on aquatic true bugs in a tropical biodiversity hotspot
}

\section{Sundar Shunmuga Velayutham ( $\nabla$ sundarstreco@gmail.com )}

S.S.Research Foundation https://orcid.org/0000-0001-6456-1147

\section{Daniel Paiva Silva}

Instituto Federal Goiano

\section{Fabio de Oliveira Roque}

Universidade Federal de Mato Grosso

Juliana Simião Ferreira

Universidade Estadual de Goias

Jani Heino

Finnish Environment Institute: Suomen ymparistokeskus

\section{Original Article}

Keywords: freshwaters, rivers, aquatic true bugs, Hemiptera, climate change, vulnerability, Western Ghats

Posted Date: February 5th, 2021

DOl: https://doi.org/10.21203/rs.3.rs-160148/v1

License: (c) (i) This work is licensed under a Creative Commons Attribution 4.0 International License.

Read Full License

Version of Record: A version of this preprint was published at Journal of Insect Conservation on February 12th, 2021. See the published version at https://doi.org/10.1007/s10841-021-00298-8. 


\section{Abstract}

Climate change is a matter of worldwide concern with severe predicted impacts on biodiversity. Here, we analysed the potential impacts of current and future climates on aquatic true bugs (Heteroptera) in relation to their distribution patterns and ecological preferences (based on a database generated from existing literature references and field collections). We considered the traits as 'species thermal range' and 'emergence period' to evaluate the future climate change impacts on the distributions of aquatic true bugs in the riverine regions of a tropical biodiversity hotspot, the Western Ghats of India. We used Species Distribution Models (SDMs) to evaluate the potential impacts of climate change on the distributions of aquatic true bugs. We modelled the distributions of twenty-six species of aquatic true bugs using different modelling tools through a carefully examined set of occurrence records to generate potential present distributions and to project these distributions into future scenarios of climate change. We observed increasing/decreasing range sizes of the species in the current and future scenarios. We found losses and increases of species' ranges in some regions, but not much variation in species richness. Similarly, no significant effect was observed in the distribution ranges for species with different duration of emergence period and thermal range in current and future climatic scenarios. Losses and gains in species richness would be concentrated in the mountainous area of the Western Ghats, whereas loss of species and the bigger difference between current and future richness will occur in the adjacent lowlands and towards central regions, including the network of protected areas of the Western Ghats. These areas are critical to buffer regional species loss in the future.

\section{Introduction}

Climate change is projected to become one of the most predominant drivers of biodiversity change by the end of this century (IPCC 2013). In particular, freshwater biodiversity is increasingly threatened by human activities, resulting in rapid and major declines in the diversity of aquatic ecosystems, habitats, and species over a wide range of scales from global to local (e.g., Dudgeon et al. 2006; Reid et al. 2019; Albert et al. 2020). Climate warming will profoundly impact the distribution, abundance, and composition of aquatic insect species and communities because it will affect species through almost all life-history traits, including emergence, growth rate, and voltinism (Bale et al. 2002; Villalpando et al. 2009). Nevertheless, the knowledge of climate change impacts on aquatic insects is poorly developed, particularly based on findings from biodiversity hotspots (Hering et al. 2009; Sundar et al. 2020).

It is expected that global warming will affect aquatic insects in many ways, ranging from changes in their distributions to local, regional, and global extinctions (Cardoso et al. 2020). However, our capability to predict the effect of climate change on different aquatic insect groups, based on field data, is variable. Considering the significant threat posed by mosquitoes to human health, the relationships between climate change and these aquatic insects are perhaps the best studied, in both experimental and modelling work, and current knowledge suggests that the ranges of mosquito-borne diseases could expand dramatically in response to climate change (Reiter 2001). Despite the increasing availability of digitized information on biodiversity data and species occurrence records (Graham et al. 2004; Newbold 
2010; Pyke and Ehrlich 2010), our knowledge about most aquatic insect species' geographic distribution is woefully incomplete to allow accurate analysis of climate change effects. This is particularly true for aquatic insects in tropical biodiversity hotspots around the world. Up to date, only one study has addressed the potential impact of climate change on stoneflies in a tropical biodiversity hotspot, i.e., the Atlantic Forest of Brazil (Silva et al. 2019). Lack of studies causes concerns because some groups of aquatic insects, such as the cold stenothermic species, are expected to be highly threatened by climate change (Hering et al. 2009). Moreover, there is recent evidence that climate change could affect each species to different degrees and that the protected areas network would not be effective to conserve species under climate change mainly because it would not cover future species distribution of aquatic insects (Sánchez-Fernández et al. 2013; Rosso et al. 2018).

In this study, we attempted to predict the distribution patterns of aquatic true bugs (Heteroptera) based on Species Distribution Modelling (SDM) tools (Elith and Leathwick 2009; Elith et al. 2010). We compared distribution changes between current and future climatic conditions in species with different emergence times and thermal ranges. Specifically, we expected that species with short emergence periods would be particularly sensitive to alterations in temperature (Kotiaho et al. 2015). Concerning the thermal range, species with narrow thermal range are expected to be more strongly threatened by climate warming compared to the species with wide thermal range (Heino et al. 2009; Silva et al. 2019). The generated database of aquatic true bugs we used in this study is from a poorly-studied tropical biodiversity hotspot, the Western Ghats of peninsular India.

\section{Methods}

The Western Ghats (latitude: $8-21^{\circ} \mathrm{N}$ ), a UNESCO World Heritage Site, among the 36 global biodiversity hotspots in the world, occupies 5th position in the economic potential of its biological resources (Shameer et al. 2016). Western Ghats' major vegetation types are moist deciduous, dry deciduous, dry shrub vegetation, semi-evergreen, evergreen, the shola and grasslands forests (Singh et al. 2002). It is a chain of mountain ranges with approximately 140,000 square kilometers (a length of $1600 \mathrm{~km}$ ) and extends from the west coast of peninsular India from the River Tapti in the north to Kanyakumari in the south. Some important rivers originate from the mountains of Western Ghats, such as Godavari, Cauvery, Krishna, Thamiraparani, and Tungabhadra (Anbalagan et al. 2012; Shameer et al. 2016).

The Western Ghats' climate is primarily influenced by the South-West monsoon between June and September when it receives the maximum rain (> $80 \%$ ). The annual rainfall varies from $2350 \mathrm{~mm}$ in the north to $7450 \mathrm{~mm}$ in the south, even though the states Karnataka, Tamil Nadu, and Kerala that comprise the Western Ghats, receive significant rainfall from the North-East monsoon from October to December (Anbalagan et al. 2012). The Western Ghats experience a tropical climate that is warm and humid during most of the year. The average annual temperature for the whole Western Ghats is around $15^{\circ} \mathrm{C}$. During winter, frost is common in some parts, and the temperature drops to freezing point. Mean temperature ranges from $20^{\circ} \mathrm{C}$ in the south to $24^{\circ} \mathrm{C}$ in the north. The coldest periods in the South Western Ghats are also the wettest and receive the most precipitation (Dahanukar et al. 2004). 
Large-scale land use changes leading to deforestation have contributed to an increase in mean temperature by $0.5^{\circ} \mathrm{C}$ and a decline in the number of rainy days (Ramachandra and Setturu 2020), which necessitates prudent landscape management strategies involving all stakeholders for conservation of the ecologically fragile Western Ghats. The primary forests have been transformed into other land-uses in the past four decades due to commercial establishments, hydroelectric projects, industries, and monoculture plantations (Ramachandra and Setturu, 2020). The main threats affecting freshwater biodiversity in the Western Ghats include pollution, biological resource use, residential and commercial development, dams and other natural system modifications, alien invasive species, agriculture, aquaculture, energy production, and mining. Stream vegetation and riparian forests have also been subjected to similar threats with direct impacts on biodiversity and indirect effects through increased sediment loads, erosion, flash floods, loss of habitats such as stagnant pools, inconsistent flow, and disappearance of primary and secondary streams (Molur et al. 2011).

\section{Species occurrence data}

First, we gathered occurrence data on aquatic true bugs in the Western Ghats from all available published literature sources (Appendix I), and the first author's (S.S.) field experience data on the distributions and ecological preferences of the aquatic bugs in the Western Ghats river basins were pooled to generate baseline data. Although this database is subjected to the prejudice of lack of uniformly designed spatial and temporal surveys, a genuine attempt was made to arrive at a tentative to standardize the information on the distribution of aquatic true bugs in the Western Ghats. In our study, six species are endemic from Western Ghats, and then our dataset and modelling strategy do not cause any bias in projecting their potential distribution across India. In the case of species that are not restricted to Western Ghats, we recognize that our approach of using only data from this region could increase the risk of artificially assigning low habitat suitability to environmental conditions in which the species could be actually living (Raes, 2012). However, as Western Ghats comprises a huge environmental variation of multiple ecoregions, we believe that our dataset is adequate to project area for most parts of India.

A potential source of criticism to the amassed occurrence dataset concerns the low availability of individual species records of occurrences (Table 1). A second criticism may concern the number of modelled species we are focusing on in this study. Mainly, this occurs because, when compared to other biological groups, insect species are generally less charismatic and the species charisma is an important driver in conservation (Mammola et al. 2020). Consequently, they are more strongly affected by the several data-related shortfalls that usually affect data for biological groups (Cardoso et al. 2011; Hortal et al. 2015). Despite potential criticisms regarding how comprehensive and extensive this dataset is, it is currently the best occurrence dataset for aquatic true bugs available in the Western Ghats. Even though a lack of large numbers of occurrences may affect modelling results, several past studies were able to produce a preliminary assessment of a given species' distribution ranges with a low number of records. We used only reliably georeferenced records of aquatic true bug species in this study. Records with strikingly incorrect georeferences (e.g., points on the sea, inverted latitude and longitude, inverted signs) were excluded from all analyses. 
Model performance depends on both sample size and species' prevalence, being the fraction of the study area occupied by the species. Previous studies involving the SDM approach were able to produce reliable species distribution prediction with a minimum of one occurrence (De Siqueira et al. 2009). Yet, a higher number of records (e.g., 10 to 50 occurrences per species) would allow us to obtain more reliable range predictions for the modelled species. Therefore, we focused only on species with at least 10 spatially unique occurrences to allow a minimally reliable distribution range to be modelled at the grid cell-size resolution we used (see below). Following the criteria mentioned above, we modelled the final set of 26 aquatic true bug species depicted in Table 1.

\section{Predictor variable processing and modelling procedures}

We obtained the 19 variables for both current and future climate conditions from Worldclim 1.4 database (Hijmans et al. 2005), considering a 2.5 arcmin ( $0.041^{\circ}$ or $4 \mathrm{~km}$ at the equator. We standardized all variables from all scenarios to have their means equal to zero and unit variances. For the current scenario, we used Principal Component Analysis (PCA) to generate orthogonal/independent variables to be used as new variables to predict the species' distribution. Using this method, we avoided model overfitting (Jiménez-Valverde et al. 2011) and decreased both the number of variables and variable collinearity in our models (Dormann et al. 2013). The first seven principal components (PCs) accounted for $\sim 97 \%$ of the original climate variables' variation. The contribution of each climatic variable to each one of the seven PCs is shown in Table 2.

The variables for the future scenarios were available from 17 atmosphere-ocean global circulation models (AOGCMs) available from Worldclim, considering the Representative-Carbon Pathway 8.5 (RCP 8.5) for 2070: ACCESS1-0, BCC-CSM1-1, CCSM4, CNRMCM5, GFDL-CM3, GISS-E2-R, HadGEM2-AO, HadGEM2-CC, HadGEM2- ES, INMCM4, IPSL-CM5A-LR, MIROC-ESM-CHEM, MIROC-ESM, MIROC5, MPIESM-LR, MRICGCM3, NorESM1-M). Under these RCP conditions, the global human population is expected to grow up to 9-12 billion people continuously. No significant socio-politic-economical changes are expected to reduce the emission of greenhouse gases significantly. According to the reports from the Intergovernmental Panel on Climate Change (IPCC), the average temperatures are expected to rise $3.7^{\circ} \mathrm{C}$, with variation from 2.6 to $4.8^{\circ} \mathrm{C}$ ). All AOGCMs had the same resolution than the current scenario and were also standardized to have the average equal to zero and unit variances. Then, we also applied a PCA to each of our 17 future scenarios by projecting the linear coefficients obtained for the current scenario on each one of them to create a dependency of each future scenario with the current one. Later, we applied a PCA to each one of the 17 AOGCMs, and also selected the first seven PCs to be used as predictor variables of these species in each future.

To predict the distribution patterns of aquatic true bugs, we used Species Distribution Modelling (SDM) methods (Elith and Leathwick 2009; Elith et al. 2010). These methods are based on correlations from climate change models with the known current occurrence records to project onto the geographic space climatically similar areas with no available distributional information of the species. These methods are being systematically used to detect potential new areas of occurrence for insect species (Almeida et al. 
2010), aiming to delimit and support active conservation actions (Nóbrega and De Marco 2011), predict suitable areas for invasive species (Silva et al. 2014; 2016), and to predict climate effects upon biodiversity for both the past (Peres et al. 2015) and future (Martins et al. 2015) climatic scenarios. These methods are based on the Biotic-Abiotic-Movement (BAM) diagram proposed by Soberón and Peterson (2005) and Soberón (2007). According to the theory involving the BAM diagram, the realized niche of species is related to the locations where the abiotic and biotic conditions would allow its occurrence and are accessible for the species.

Since many of the species we modelled had very few occurrence records, we used the Maximum Entropy method (abbreviated as "MaxEnt" hereafter; Phillips et al. 2006; Phillips and Dudík 2008) as our modelling method. The MaxEnt is a machine-learning presence/pseudo-absence method that is reliable when the number of occurrences available for modelling a species distribution is limited (Hernandez et al. 2006; Pearson et al. 2007). In our modelling procedures with MaxEnt, we only used both linear and quadratic features to simplify the biological interpretation of distribution models (Elith et al. 2011; Anderson and Raza 2011).

We bootstrapped our species occurrence dataset into two subsets in our modelling procedures, containing $70 \%$ of the occurrences for model training and the remaining $30 \%$ as testing datasets. We also used pseudo-absences along the geographic space by first establishing a multivariate bioclimatic environmental space. Then, we allocated the pseudo-absences in geographic areas that were climatically outside of such environmental space as previously done in other studies (VanDerWal et al. 2009; Lobo and Tognelli 2011). This allows MaxEnt to have higher discriminatory and explanatory capacities and a lower probability of climatic conditions impossible to be accessed by the species to affect the modelled species' response curves (Barve et al. 2011). Finally, we also restricted the available climatic information to train the models with the ecoregions shape file obtained from World Wildlife Fund website (https://www.worldwildlife.org/biomes) to the ecoregions within the Western Ghats' known occurrences of the modelled species. This approach avoids model over prediction and unreliable predictions for the species distribution range (VanDerWal et al. 2009; Giovanelli et al. 2010; Acevedo et al. 2017).

In the modelling, we considered the "lowest presence training" (LPT hereon; Pearson et al. 2007) as the threshold value to cut the suitability matrices obtained for all modelled species in all scenarios into presence/absence maps. In ecological terms, the LPT threshold identifies pixels that are predicted as minimally suitable for the species' occurrences as its actual observed records. Since the species' realized ecological niches may be underestimated, given the small number of occurrences, we intended to estimate a distribution range for these species that could be near their true distribution range by using this threshold.

We considered the Jaccard similarity index, as proposed by Leroy et al. (2018), to be used as the evaluation metric in our study. This metric varies from 0 to 1 , where values equal to or higher than 0.7 are considered acceptable. One of the main advantages of using this metric is that it does not need pseudoabsences to evaluate the produced models, being able to produce more reliable predictions than those 
that consider pseudo-absences to generate contingency tables for model evaluation [e.g. area under the curve (Fielding and Bell, 1997) or true skill statistics (Allouche et al. 2006)]. To generate the final ensemble distribution for each one of the species we modelled, we used a weighted mean based on the Jaccard similarity index to ensemble the final distribution range for all species in all scenarios. We ran all analyses with the ENMTML R package by Andrade et al. (2020).

We follow general classification proposed by Hering et al. (2009) to classify ecological and distributional traits, i.e. species thermal range (narrow $<20^{\circ} \mathrm{C}$ ) and duration of emergence period (short $<50$ days) for the occurrences from the Western Ghats. Unfortunately, there is little information available to figure out if aquatic true bug species that occur within a narrow thermal range are necessarily thermal specialists in terms of their fundamental thermal niche. So, to avoid this problem, we classified them as "species with narrow thermal range" and "species with wide thermal range". The species thermal range was defined according to the temperature range in which aquatic true bugs occur in nature because no physiological information was available. We checked whether the species with differences in their 1) duration of emergence period (Short $<50$ days) and 2$)$ thermal range $\left(<20^{\circ} \mathrm{C}\right)$ (Table 1$)$ showed any differences in distribution ranges in current and future scenarios. Therefore, we used Factorial Repeated Measures ANOVAs using the species' analyzed traits and climatic scenario as predictor variables and their distribution range size in each scenario as the resulting variable. Since we are using the very same occurrences to generate both current and future predictions of our insect species, the predictions are dependent one another, what requires the use of a repeated measures ANOVA analysis. We also used a Pearson correlation to check if the species' ranges in both current and future scenarios were correlated. Finally, we also computed the species richness and evaluated the species richness change in both scenarios, by summing the final modelled ranges for all species in specific each scenario.

\section{Results}

In general, our models reached highly acceptable Jaccard values $(0.947 \pm 0.051$; average \pm standard deviation), a result that indicates the predicted ranges for all 26 species we modelled here were adequate. Several species reached Jaccard values equal to 1 , whereas the one which reached the lowest value was D. rusticus (Table 1). The overall contributions of each variable to the PCs we used as new environmental variables in each one of the climatic scenarios we modelled may be checked in Table 2.

After comparing the distributions of the species in both current and future scenarios (Figs. 1 and 2), we observed that there were practically no differences in the species distributing range size in each scenario. Yet, some patterns were noticeable. For instance, most species $(n=16)$ showed some range increase, while very few of them showed decreased ranges when current and future ranges were compared (Fig. 3A). Among these species, A. hyalinipennis ( +86\%), H. indicus ( + 70\%), L. grossus $(\sim+41 \%)$, and $D$. rusticus $(\sim+33 \%)$ were the species that showed ranges increasing the most from the current to the future climatic scenario. However, some species $(\mathrm{n}=9)$ showed distribution ranges decreasing from the current to the future scenarios (e.g. A. barbatus, $A$. s. sardeus, C. asiaticus, $C$. productus, D. molestus, H. rotundatus, L. maculatus, M. communis, and M. s. scutellaris). Among these last species, $H$. 
rotundatus ( $\sim-80 \%)$, C. asiaticus ( 31\%), A. exiguus ( $-30 \%)$, and L. maculatus ( $-20 \%)$ were the species that were predicted to exhibit the highest range loss. In general, all species had their current range without much difference in relation to their future range, although many species had a narrow distribution range in both scenarios, while very few species had a broad distribution range in both scenarios (Fig. 3B). We did not observe any effect of the species duration of the emergence period $(F 1,23=1.119 ; p=0.301)$ and thermal range $(F 1,23=1.119 ; p=0.301)$ on the species ranges in both current and future scenarios.

Finally, considering the modelled species richness in both current (Fig. 4A) and future (Fig. 4B) scenarios, we did not observe a strong difference between the scenarios. Yet, when we subtracted the current species richness from the future species richness, we observed that there was loss of species richness in some regions, whereas there were increases in the modelled species richness in others (Fig. 4C).

\section{Discussion}

Our study adds evidence from the Western Ghats that some aquatic insects will face significant threats of declining habitat suitability for species due to climate change in the coming years. However, our findings did not support the idea that their response to climate change can be easily predicted based on ecological traits, such as species thermal range and emergence period. Our results also indicated that the altitudinal and latitudinal ranges of the Western Ghats are key characteristics to retain the balance between gains and loss in the distribution of aquatic true bugs.

The emergence period of aquatic true bug species largely depends on temperature and can vary from less than 50 days in some species at high temperatures to more than one year under colder temperature conditions (Saulich and Musolin 2007). It is expected that species with short emergence periods are particularly sensitive to temperature rise, leading to accelerated development, more generations per year, and, consequently, changes in their distribution patterns. Contrary to this expectation, we did not find an effect of duration emergence time in both current and future scenarios. A possible explanation could be related to the intensity of climate change in the region that may not be strong enough to elicit clear responses of species with different emergence periods to warming. However, considering that, in the $2030 \mathrm{~s}$, the mean annual temperatures of the Western Ghats region are projected to rise from $26.8 \pm 0.4^{\circ} \mathrm{C}$ to $27.5 \pm 0.4^{\circ} \mathrm{C}$ (MoEFCC, 2010), we believe that the lack of relationship can also be attributed to the high variability in the ecological requirements and behavioral responses of various taxa to climate warming, which are not represented by simple categories of emergence periods we used in this study.

The thermal range of aquatic true bugs did not affect our findings. It is a surprising finding given that there are many species with narrow thermal range in the Western Ghats and some species with narrow thermal range could have wider thermal tolerances and the lack of differences in distribution patterns observed in this study could be affected by this limitation. The topographic, altitudinal, and latitudinal variation may promote opportunities to some species to change their distribution, resulting in no net effect on their distributional range size. Moreover, aquatic true bug species in the Western Ghats may have experienced strong temperature variation along the latitudinal and altitudinal gradient (increasing 
and decreasing cycles) in the Quaternary, which may generate resilient species with wide thermal range. Variable spatio-temporal patterns of precipitation (and the resultant expansion and contraction of suitable habitats, droughts, floods and so on) are also essential to promote opportunities for species resilience and co-existence through niche partitioning (Brown et al. 2020). In this context, new studies about the effect of climate change on aquatic insects' traits should address the potential impacts of both temperature and precipitation.

Our results showed that climate warming would decrease the distribution ranges of nine species of aquatic true bugs. All species predicted to experience range loss in the coming years would be restricted to the mountainous part of the Western Ghats, and some species, such as $H$. rotundatus, $C$. asiaticus, would be limited to the extreme south of the region (close to the Sri Lanka Bridge). Previous studies evaluating the effects of climate change on the distribution of aquatic insects (e.g. Silva et al. 2019; Tierno de Figueroa et al. 2010; Domisch et al. 2013) have already shown that some species will be impacted. This trend is even more concerning if we think about the predicted hydrological changes expected to occur worldwide (Rodell et al. 2018), where many catchments around the planet will exhibit drier conditions (Rolls et al. 2018). Although abundance changes at the community level may not necessarily occur (Jourdan et al. 2018), sensitive species may suffer range size decreases in some areas, especially those surrounded by intensified agriculture. The changes in the distribution ranges for our modelled species were not as evident as observed for other species in previous studies involving SDMs (e.g. Tierno de Figueroa et al. 2010; Domisch et al. 2013; Shah et al. 2014). Such differences may be related to the fact that the species we modelled here are more adapted to the climate conditions near the Tropics than the species modelled in previous studies conducted in subtropical and temperate areas. Therefore, these species may be considered more climate generalists, and such a feature may indicate a better ability to cope with climate change. Yet, considering the ecological and economic importance of aquatic true bugs as bioindicators and biological control agents (Schaefer and Panizzi 2000), careful monitoring of their range shifts can pinpoint the species requiring particular conservation attention.

Losses and gains in species richness would be concentrated in the mountainous area of Western Ghats, whereas loss of species and the bigger difference between current and future richness will occur in the adjacent lowlands and towards central regions. This finding suggests that the Western Ghats' topography and latitudinal range can buffer regional species loss in the future. Furthermore, in India, anthropogenic pressures on biodiversity are concentrated in the lowlands, including near big cities (e.g., Mumbai, Pune), which will exacerbate the loss of biodiversity in the adjacent lowlands of the Western Ghats. Besides, the network of protected areas and complementary conservation strategies should include a range of lowlands and uplands in the Western Ghats, particularly the transitional areas between uplands and lowlands where considerable changes of species distributions are expected. Most protected areas are located in the mountainous regions of the Western Ghats, and they cover a sizeable latitudinal variation in the region. However, little information about the effective conservation of aquatic biodiversity is available in this region. 
Despite of the results we obtained in this study, it is of utmost important to stress that SDMs are not silver bullets. These methods are being significantly used to determine distribution range hypotheses concerning several different objectives, such as: 1) delimitation of conservation areas (e.g., Nóbrega and

De Marco 2011); 2) determine the impacts of invasive species and whether their niches change during the invasion process (e.g., Faleiro et al. 2015; Montalva et al. 2017; Silva et al. 2016; 2017); 3) evaluate the potential impacts of past and future climatic changes on biodiversity (e.g., Peres et al. 2015; Carvalho et al. 2017); and 4) pinpoint interesting areas for future sampling and to indicate species under-sampled regions. Still, considering the biotic-Abiotic-Movement (aka BAM) diagram (Soberón and Peterson 2005; Soberón 2007), these methods are mere simplification of the reality, since important ecological processes, such as migration and biotic interactions are not fully accessed, while the importance of abiotic processes may be overestimated. Considering the technology and theoretical background we know by now, we are not able to solve and include and all of these ecological processes into our models. Although our models are wrong, they are still useful (Box, 1979), and with our results we provided a first glimpse on how the distribution range of these modelled species may be now and in near future. We also hope that our research serves to incentivize future research to be produced in this area of the globe, with these and other insect species, in order to fight the Wallacean shortfall that severely affect our knowledge on insect species (Hortal et al. 2015; Cardoso et al. 2011).

To conclude, our current observations suggested that climate change is a potentially significant threat to aquatic true bugs, although habitat fragmentation and degradation may have larger effects than climate change on these species' distributions in the tropics. Also, a considerable portion of aquatic true bugs may be driven to local or regional extinction in India because of rapid changes in temperatures or extreme climate events, even if the possibility of altitudinal and latitudinal range shifts cannot be fully neglected. We hope that our findings spur additional studies on the status, diversity, and distributions of aquatic true bugs in the tropics.

\section{Declarations}

\section{ACKNOWLEDGMENTS}

The author (S. S.) thanks Science and Engineering Research Board (SERB), Department of Science and Technology (DST), Govt. of India for financial support under Fast Track Young Scientist Scheme (File. No. SB/FT/LS-266/2012). DPS and FOR are supported by a productivity grant by Conselho Nacional de Desenvolvimento Científico e Tecnológico (CNPq, proc. Number 304494/2019-4 and 302755/2018-7, respectively). We thank Institutional Program of Internationalization sponsored by Coordination for the Improvement of Higher Education Personnel (Capes-Print number 41/2017).

\section{CONFLICTS Of INTEREST STATEMENT:}

"NONE" 


\section{References}

Acevedo P, Jiménez-Valverde A, Lobo JM, Real, R (2017) Predictor weighting and geographical background delimitation: two synergetic sources of uncertainty when assessing species sensitivity to climate change. Clim Change 145,131-143. https://doi.org/10.1007/s1058 4-017-2082-1

Albert JS, Destouni G, Duke-Sylvester SM, Magurran AE, Oberdorff T, Reis RE, Winemiller KO, Ripple, WJ (2020) Scientists' warning to humanity on the freshwater biodiversity crisis. Ambio 1-10. https://doi.org/10.1007/s13280-020-01318-8.

Allouche 0, Tsoar A, Kadmon R (2006) Assessing the accuracy of species distribution models: prevalence, Kappa and the True Skill Statistic (TSS). J Appl Ecol 43, 1223-1232.

Almeida MC, Côrtes LG, De Marco Jr, P (2010) New records and a niche model for the distribution of two Neotropical damselflies: Schistolobos boliviensis and Tuberculobasis inversa (Odonata: Coenagrionidae). Insect Conserv. Divers. 3, 252-256. doi:10.1111/j.1752-4598.2010.00096.x

Anbalagan S, Dinakaran S, Krishnan M (2012) Spatio-temporal Dynamics of Leaf Litter Associated Macroinvertebrates in Six River Basins of Peninsular India. Ecologia, 2, 1-11.

DOI: 10.3923/ecologia.2012.1.11

Anderson RP, Raza A (2010) The effect of the extent of the study region on GIS models of species geographic distributions and estimates of niche evolution: preliminary tests with montane rodents (genus Nephelomys) in Venezuela. J Biogeogr 37, 1378-1393. doi: 10.1111/j.1365-2699.2010.02290.x

Andrade AFA, Velazco SJE, De Marco Jr, P (2020) ENMTML: An R package for a straightforward construction of complex ecological niche models. Environ. Model. Softw. 125, 104615. doi:10.1016/j.envsoft.2019.104615

Bale JS, Masters GJ, Hodkinson ID, Awmack C, Bezemer TM et al (2002) Herbivory in global climate change research: direct effects of rising temperature on insect herbivores. Global Change Biology $8,1-$ 16.

Barve N, Barve V, Jiménez-Valverde A, Lira-Noriega A, Maher SP, Peterson AT, Soberpn J, Villalobos F (2011) The crucial role of the accessible area in ecological niche modeling and species distribution modeling. Ecological Modelling 22211, 1810-1819. https://doi.org/10.1016/j.ecolm odel.2011.02.011

Box GEP (1979) Robustness in the strategy of scientific model building. In: Launer RL, Wilkinson GN, editors. Robustness in Statistics. Academic Press. pp. 201-236. doi:10.1016/B978-0-12-438150-6.500182

Brown SC, Wigle TML, Otto-Bliesne BL et al (2020) Persistent Quaternary climate refugia are hospices for biodiversity in the Anthropocene. Nat. Clim. Chang. 10, 244-248. https://doi.org/10.1038/s41558-0190682-7 
Cardoso P, Erwin TL, Borges PAV, New TR (2011) The seven impediments in invertebrate conservation and how to overcome them. Biol Conserv 144:2647-2655.

Cardoso P, Barton PS, Birkhofer K, Chichorro F, Deacon C, Fartmann T et al (2020) Scientists' warning to humanity on insect extinctions. Biol. Conserv 242, 108426.

Carvalho DL, Sousa-Neves T, Cerqueira P V, Gonsioroski G, Silva SM, Silva DP, et al. (2017) Delimiting priority areas for the conservation of endemic and threatened Neotropical birds using a niche-based gap analysis. PLoS One.12: e0171838. doi:10.1371/journal.pone.0171838

Dahanukar N, Rupesh R, Bhat A (2004) Distibution, endemism and threat status of freshwater fishes in the Western Ghats of India. J Biogeography 31, 123-136. https://doi.org/10.1046/j.0305-

0270.2003.01016.x

De Siqueira MF, Durigan G, De Marco Jr P, Peterson AT (2009) Something from nothing: Using landscape similarity and ecological niche modeling to find rare plant species. J Nat Conserv 17:25-32. doi: 10.1016/j.jnc.2008.11.001

Domisch S, Araújo MB, Bonada N, Pauls SU, Jähnig SC, Haase P (2013) Modelling distribution in European stream macroinvertebrates under future climates. Glob. Chang. Biol. 19, 752-762. doi:10.1111/gcb.12107

Dormann CF, Elith J, Bacher S et al (2013) Collinearity: A review of methods to deal with it and a simulation study evaluating their performance. Ecography (Cop) 36, 27-46. doi: 10.1111/j.16000587.2012.07348.x

Dudgeon D et al (2006) Freshwater biodiversity: importance, threats, status and conservation challenges. Biological Reviews 81, 163-182.

Elith J, Kearney M, Phillips S (2010) The art of modelling range shifting species. Methods Ecol Evol 1, 330-342.

Elith J, Leathwick JR (2009) Species distribution models: ecological explanation and prediction across space and time. Annu Rev Ecol Evol Syst 40, 677-697.

Elith J, Phillips SJ, Hastie T, Dudík M, Chee YE et al (2011) A statistical explanation of MaxEnt for ecologists. Divers. Distrib. 17, 43-57.

Faleiro FV, Silva DP, Carvalho RA, Särkinen T, De Marco Jr P (2015) Ring out the bells, we are being invaded! Niche conservatism in exotic populations of the Yellow Bells, Tecoma stans (Bignoniaceae). Nat Conserv. 13, 24-29. doi:10.1016/j.ncon.2015.04.004

Fielding AH, Bell JF (1997) A review of methods for the assessment of prediction errors in conservation presence/absence models. Environ. Conser. 24, 38-49. 
Giovanelli JGR, et al (2010) Modeling a spatially restricted distribution in the Neotropics: how the size of calibration area affects the performance of five presence-only methods. Ecol. Model. 221, 215- 224.

Graham CH, Ferrier S, Huettman F, Moritz C, Peterson AT (2004) New developments in museum-based informatics and applications in biodiversity analysis. Trends Ecol. Evol. 19, 497-503.

Hernandez PA, Graham CH, Master LL, Albert DL (2006) The effect of sample size and species characteristics on performance of different species distribution modeling methods. Ecography (Cop) 29 , 773-785.

Heino J, Virkkala R, Toivonen H (2009) Climate change and freshwater biodiversity: detected patterns, future trends and adaptations in northern regions. Biological Reviews 84: 39-54.

Hering D et al (2009) Potential impact of climate change on aquatic insects: a sensitivity analysis for European caddisflies (Trichoptera) based on distribution patterns and ecological preferences. Aquatic Sciences 71, 3-14.

Hijmans RJ, Cameron SE, Parra JL, Jones PG, Jarvis A (2005) Very high resolution interpolated climate surfaces for global land areas. Int. J. Climatol. 25, 1965- 78.

Hortal J, de Bello F, Diniz-Filho JAF et al (2015) Seven Shortfalls that Beset Large-Scale Knowledge of Biodiversity. Annu Rev Ecol Evol Syst 46:523-549. doi: 10.1146/annurev-ecolsys-112414-054400

IPCC (2013) Climate Change 2013: The Physical Science Basis. Contribution of Working Group I to the Fifth Assessment Report of the Intergovernmental Panel on Climate Change [T.F. Stocker, D. Qin, G.-K. Plattner, M. Tignor, S.K. Allen, J. Boschung, A. Nauels, Y. Xia, V. Bex \& P.M. Midgley (Eds.)]. Cambridge University Press, Cambridge, United Kingdom and New York, NY, USA, 1535 pp.

Jiménez-Valverde A, Lobo JM (2011) Tolerance limits, animal. In: Simberloff D Rejmánek M (eds) Encyclopedia of biological invasions. University of California Press, CA, pp 661-663.

Jourdan J et al (2018) Effects of changing climate on European stream invertebrate communities: A longterm data analysis. Sci. Total Environ. 621, 588-599. doi:10.1016/j.scitotenv.2017.11.242

Kotiaho JS, Kaitala V, Komonen A, Paivinen J (2005) Predicting the risk of extinction from shared ecological characteristics. Proceedings of the National Academy of Sciences of the United States of America 102(6), 1963-1967.

Leroy B et al (2018) Without quality presence-absence data, discrimination metrics such as TSS can be misleading measures of model performance. - J. Biogeogr. 45, 1994- 2002.

Lobo JM, Tognelli MF (2011) Exploring the effects of quantity and location of pseudo-absences and sampling biases on the performance of distribution models with limited point occurrence data. J. Nat. Conserv. 19: $1-7$. 
Mammola S, Riccardi N, Prié V, Correia R, Cardoso P, Lopes-Lima M, Sousa R (2020) Towards a taxonomically unbiased European Union biodiversity strategy for 2030. Proc. R. Soc. B 287: 20202166. https://doi.org/10.1098/rspb.2020.2166

Martins AC, Silva DP, De Marco Jr P, Melo GAR (2015) Species conservation under future climate change: The case of Bombus bellicosus, a potentially threatened South American bumblebee species. J. Insect Conserv. 19, 33-43. doi:10.1007/s10841-014-9740-7

MoEFCC (2010) Climate Change and India: A 4X4 Assessment - A Sectoral and Regional Analysis for 2030s. INCCA Report \#2. INCCA: Indian Network for Climate Change Assessment. 160 p.

Molur S, Smith KG, Daniel BA, Darwall WRT (Compilers) (2011) The Status and Distribution of Freshwater Biodiversity in the Western Ghats, India. Cambridge, UK and Gland, Switzerland: IUCN, and Coimbatore, India: Zoo Outreach Organization.

Montalva J, Sepulveda V, Vivallo F, Silva DP (2017) New records of an invasive bumble bee in northern Chile: Expansion of its range or new introduction events? J Insect Conserv. 21, 657-666. doi:10.1007/s10841-017-0008-x

Newbold T (2010) Applications and limitations of museum data for conservation and ecology, with particular attention to species distribution models. Prog. Phys. Geogr. 34, 3-22.

doi:10.1177/0309133309355630

Nóbrega CC, De Marco Jr P (2011) Unprotecting the rare species: a niche-based gap analysis for odonates in a core Cerrado area. Divers. Distrib. 17, 491-505.

Pearson RG, Raxworthy CJ, Nakamura M, Peterson AT (2007) Predicting species distributions from small numbers of occurrence records: a test case using cryptic geckos in Madagascar. J Biogeogr 34,102-117.

Peres EA, Sobral-Souza T, Perez MF, Bonatelli IAS, Silva DP, Silva MJ, Solferini VN (2015) Pleistocene Niche Stability and Lineage Diversification in the Subtropical Spider Araneus omnicolor (Araneidae). PLoS One 10, e0121543. doi:10.1371/journal.pone.0121543

Phillips SJ, Anderson RP, Schapire RE (2006) Maximum entropy modelling of species geographic distributions. Ecol Model 190, 231-259.

Phillips SJ, Dudík M (2008) Modeling of species distributions with Maxent: new extensions and a comprehensive evaluation. Ecography 31, 161-175.

Pyke GH, Ehrlich PR (2010) Biological collections and ecological/environmental research: A review, some observations and a look to the future. Biol. Rev. 85, 247-266.

Raes N (2012) Partial versus full species distribution models. Nat. a Conserv. 10, 127-138. 
Ramachandra TV, Setturu B (2019) Carbon Sequestration Potential of the Forest Ecosystems in the Western Ghats, a Global Biodiversity Hotspot. Nat Resour Res., 1-19.https://doi.org/10.1007/s11053-01909588-0

Reid AJ et al (2019) Emerging threats and persistent conservation challenges for freshwater biodiversity. Biol Rev, 94, 849-873. doi:10.1111/brv.12480

Reiter P (2001) Climate change and mosquito-borne disease. Environmental health perspectives, 109 Suppl 1 (Suppl 1), 141-161. https://doi.org/10.1289/ehp.01109s1141

Rodell M, Famiglietti JS, Wiese DN, Reager JT, Beaudoing HK, Landerer FW, Lo M.-H (2018) Emerging trends in global freshwater availability. Nature 1. doi:10.1038/s41586-018-0123-1

Rolls RJ, Heino J, Ryder DS, Chessman BC, Growns IO, Thompson RM Gido KB (2018) Scaling biodiversity responses to hydrological regimes. Biol Rev, 93: 971-995. doi:10.1111/brv.12381

Rosso A, Aragón P, Acevedo F, Doadrio I, García-Barros E, Lobo JM, Munguira ML, Monserrat, VJ, Palomo J, Pleguezuelos JM, Romo H, Triviño V, Sánchez-Fernández D (2018) Effectiveness of the Natura 2000 network in protecting Iberian endemic fauna. Anim. Conserv, 21, 262-271. DOI: 10.1111/acv.12387

Sánchez-Fernández D, Abellán P, Picazo F, Millán A, Ribera I, Lobo JM (2013) Do protected areas represent species' optimal climatic conditions? A test using Iberian water beetles. Diversity and distributions, 19(11): 1407- 1417. DOI: 10.1111/ddi.12104

Saulich AH, Musolin DL (2007) Seasonal development of aquatic and semi-aquatic true bugs (Heteroptera). St Petersburg University, St Petersburg, 205 pp.

Schaefer CW, Panizzi AR (2000) Heteroptera of econornic importance. CRC Press, Boca Raton.

Shah DN, Domisch S, Pauls SU, Haase P, Jähnig SC (2014) Current and Future Latitudinal Gradients in Stream Macroinvertebrate Richness Across North America. Freshw. Sci. 33, 1136-1147. doi:10.1086/678492

Shameer PS, Rameshkumar KB, Mohanan N (2016) Diversity of Garcinia species in the Western Ghats, In: Rameshkumar KB (ed) Diversity of Garcinia species in the Western Ghats: Phytochemical Perspective. Jawaharlal Nehru Tropical Botanic Garden and Research Institute Palode, Akshara Offset Press Thiruvananthapuram, India. pp. 01-18.

Silva DP, Gonzalez VH, Melo GAR, Lucia M, Alvarez LJ, De Marco Jr P (2014) Seeking the flowers for the bees: Integrating biotic interactions into niche models to assess the distribution of the exotic bee species Lithurgushuberi in South America. Ecol. Modell. 273, 200-209. doi:10.1016/j.ecolmodel.2013.11.016

Silva DP, Vilela B, Buzatto BA, Moczek AP, Hortal J (2016) Contextualized niche shifts upon independent invasions by the dung beetle Onthophagus taurus. Biol. Invasions 18, 3137-3148. doi:10.1007/s10530- 
Silva DP, Dias AC, Lecci LS, Simião-Ferreira J (2019) Potential Effects of Future Climate Changes on Brazilian Cool-Adapted Stoneflies (Insecta: Plecoptera). Neotrop. Entomol. 48, 57-70. doi:10.1007/s13744-018-0621-8

Singh MP, Singh BS, Dey S (2002). Plant diversity and Taxonomy. Daya Publishing House, New Delhi, pp. 108-121.

Soberón J, Peterson AT (2005) Interpretation of models of fundamental ecological niches and species' distributional areas. Biodivers. Informatics 2, 1-10.

Soberón J (2007) Grinnellian and Eltonian niches and geographic distributions of species. Ecol. Lett. 10, 1115-1123. doi:10.1111/j.1461-0248.2007.01107.x

Sundar S, Heino J, Roque FO et al (2020) Conservation of freshwater macroinvertebrate biodiversity in tropical regions. AquaticConserv: Mar Freshw Ecosyst. 1-13. https://doi.org/10.1002/aqc.3326

Tierno de Figueroa JM, López-Rodríguez MJ, Lorez A, Graf W, Schimidt-Kloiber A, Hering D, Lorenz A, Graf W, Schmidt-Kloiber A, Hering D (2010) Vulnerable taxa of European Plecoptera (Insecta) in the context of climate change. Biodivers. Conserv. 19, 1269-1277. doi:10.1007/s10531-009-9753-9

VanDerWal J, Shoo LP, Graham C, Williams SE (2009) Selecting pseudo-absence data for presence-only distribution modeling: how far should you stray from what you know? Ecological Modelling 220, 589594.

Villalpando SN, William RS, Norby RJ (2009) Elevated air temperature alters an old-field insect community in a multifactor climate change experiment. Global Change Biology 15, 930-942.

\section{Tables}

Table 1 - Jaccard similarity index obtained by the distribution models of the 26 species we modeled and the species traits we considered in some of our analyses. 
Records

Species

Agraptocorixa hyalinipennis Fabricius 1803) (Corixidae)

Anisops barbatus Brooks 1951 (Notonectidae)

Anisops campbelli Distant 1918 (Notonectidae)

Anisops cavifrons Brooks 1951 (Notonectidae)

Anisops exiguus Horváth 1919 (Notonectidae)

Anisops sardeus sardeus Herrich-Schäffer 1850

(Notonectidae)

Cercotmetus asiaticus Amyot \& Serville 1843 (Nepidae)

Cercotmetus pilipes Dallas 1850 (Nepidae)

Cylindrostethus productus Spinola 1840 (Gerridae)

Diplonychus annulatus Fabricius 1781 (Belostomatidae)

Diplonychus molestus Dufour 1863 (Belostomatidae)

Diplonychus rusticus Fabricius 1781 (Belostomatidae)

Enithares hungerfordi Brooks 1948 (Notonectidae)

Heleocoris indicus Montandon 1897 (Naucoridae)

Heleocoris rotundatus Montandon 1908 (Naucoridae)

Heleocoris vicinus Montandon 1910 (Naucoridae)

Laccotrephes griséus Gúerin-Méneville 1844 (Nepidae)

Laccotrephes grossus Fabricius 1787 (Nepidae)

Laccotrephes maculatus Fabricius 1775 (Nepidae)

Metrocoris communis Distant 1910 (Gerridae)

Micronecta desertana desertana Distant 1920

(Corixidae)

Micronecta scutellaris scutellaris Kirkaldy 1897

(Corixidae)

Nerthra indica Atkinson 1888 (Gelastocoridae)

Ranatra elongata Fabricius 1790 (Nepidae)

Ranatra filiformis Fabricius 1790 (Nepidae)

Sigara pruthiana_Hutchinson 1940 (Corixidae)
Jaccard Emergence

index period

$\begin{array}{cccc}11 & 1.000 & \text { Short } & \text { Narrow } \\ 17 & 0.933 & \text { Short } & \text { Narrow } \\ 12 & 1.000 & \text { Short } & \text { Narrow } \\ 15 & 1.000 & \text { Short } & \text { Narrow } \\ 15 & 1.000 & \text { Short } & \text { Narrow }\end{array}$

14

$\begin{array}{llll} & 0.875 & \text { Long } & \text { Wide } \\ 10 & 0.909 & \text { Long } & \text { Wide } \\ 12 & 0.917 & \text { Long } & \text { Wide } \\ 15 & 1.000 & \text { Long } & \text { Wide } \\ 10 & 0.900 & \text { Long } & \text { Wide } \\ 10 & 1.000 & \text { Long } & \text { Wide }\end{array}$

$17 \quad 0.833 \quad$ Short Narrow

111.000 Long Wide

$15 \quad 0.923$ Short Narrow

161.000 Long Wide

180.929 Long Wide

$20 \quad 0.944$ Long Wide

$110.917 \quad$ Long Wide

$18 \quad 0.941 \quad$ Long Wide

$15 \quad 0.875 \quad$ Short Narrow

$15 \quad 1.000$

$14 \quad 1.000$

Long Wide

\begin{tabular}{rrrr} 
& & Short & Narrow \\
24 & 0.917 & Short & Narrow \\
19 & 0.875 & Long & Wide \\
16 & 0.938 & Long & Wide \\
10 & 1.000 & Short & Narrow \\
\hline
\end{tabular}


Table 2 - Summary of the Principal Component Analysis, which was used to provide the principal components (PC), used as environmental layers. Each cell value represents the individual loadings of each variable on each of the PCs. The PCs, individual, and accumulated proportions of each PCs are also shown.

\begin{tabular}{|c|c|c|c|c|c|c|c|}
\hline Variables & PC1 & PC2 & PC3 & PC4 & PC5 & PC6 & PC7 \\
\hline Annual Mean Temperature (bio1) & 0.325 & 0.223 & -0.029 & 0.055 & -0.039 & 0.046 & 0.028 \\
\hline MeanDiurnal Range (bio2) & -0.227 & 0.287 & 0.080 & -0.021 & 0.192 & 0.125 & 0.419 \\
\hline Isothermality (bio3) & 0.151 & -0.202 & -0.294 & -0.352 & 0.137 & 0.074 & 0.627 \\
\hline Temperature Seasonality (bio4) & -0.249 & 0.226 & 0.180 & 0.301 & 0.161 & 0.183 & 0.006 \\
\hline Max Temperature of Warmest Period (bio5) & 0.222 & 0.333 & 0.038 & 0.106 & 0.056 & 0.008 & -0.032 \\
\hline Min Temperature of Coldest Period (bio6) & 0.374 & 0.060 & -0.117 & -0.047 & -0.075 & -0.031 & -0.054 \\
\hline Temperature Annual Range (bio7) & -0.220 & 0.296 & 0.189 & 0.178 & 0.155 & 0.047 & 0.031 \\
\hline Mean Temperature of Wettest Quarter (bio8) & 0.246 & 0.283 & 0.038 & 0.168 & -0.029 & 0.192 & 0.152 \\
\hline Mean Temperature of Driest Quarter (bio9) & 0.311 & 0.204 & -0.050 & 0.008 & 0.068 & -0.040 & 0.008 \\
\hline Mean Temperature of Warmest Quarter (bio10) & 0.262 & 0.301 & 0.023 & 0.118 & 0.023 & 0.055 & -0.003 \\
\hline Mean Temperature of Coldest Quarter (bio11) & 0.364 & 0.121 & -0.084 & -0.063 & -0.074 & -0.036 & 0.003 \\
\hline Annual Precipitation (bio12) & 0.220 & -0.252 & 0.343 & 0.069 & -0.009 & 0.040 & -0.067 \\
\hline Precipitation of Wettest Period (bio13) & 0.200 & -0.200 & 0.433 & -0.055 & 0.082 & -0.091 & -0.005 \\
\hline Precipitation of Driest Period (bio14) & 0.091 & -0.195 & -0.239 & 0.491 & 0.242 & -0.331 & 0.252 \\
\hline Precipitation Seasonality (bio15) & -0.042 & 0.185 & 0.408 & -0.186 & 0.088 & -0.606 & 0.353 \\
\hline Precipitation of Wettest Quarter (bio16) & 0.204 & -0.203 & 0.435 & 0.009 & 0.037 & -0.070 & -0.065 \\
\hline Precipitation of Driest Quarter (bio17) & 0.062 & -0.230 & -0.152 & 0.550 & 0.183 & -0.203 & 0.004 \\
\hline Precipitation of Warmest Quarter (bio18) & 0.039 & -0.222 & 0.250 & 0.294 & -0.457 & 0.435 & 0.447 \\
\hline Precipitation of Coldest Quarter (bio19) & 0.132 & -0.168 & 0.091 & -0.131 & 0.746 & 0.419 & -0.074 \\
\hline Proportion (\%) of variatiol & 0.350 & 0.298 & 0.128 & 0.087 & 0.050 & 0.030 & 0.021 \\
\hline Cumulative variation (\%) & 0.350 & 0.648 & 0.777 & 0.863 & 0.913 & 0.943 & 0.964 \\
\hline
\end{tabular}

\section{Figures}



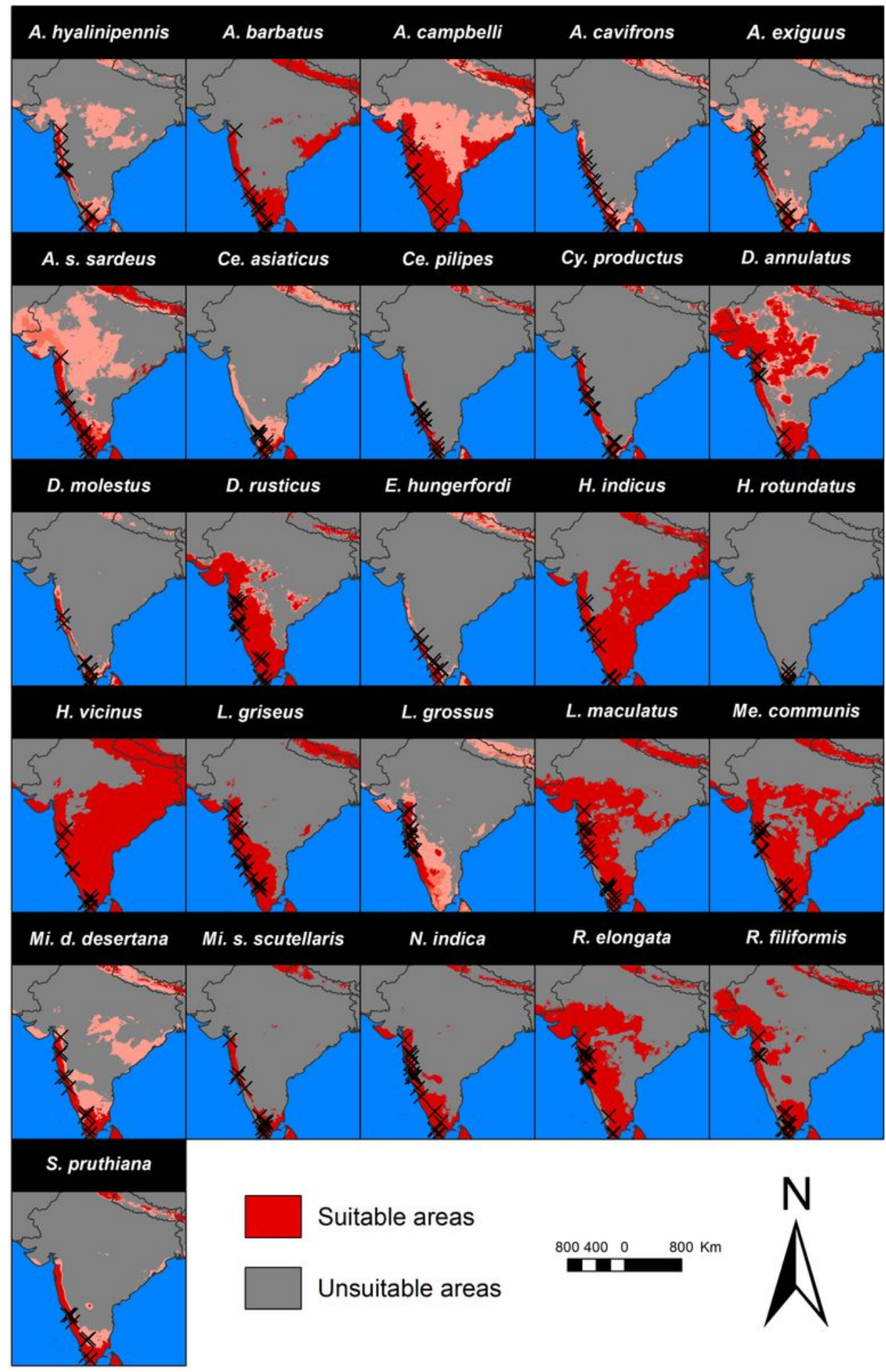

\section{Figure 1}

Current distributions of the 26 species of aquatic true bugs we modeled in this study. 


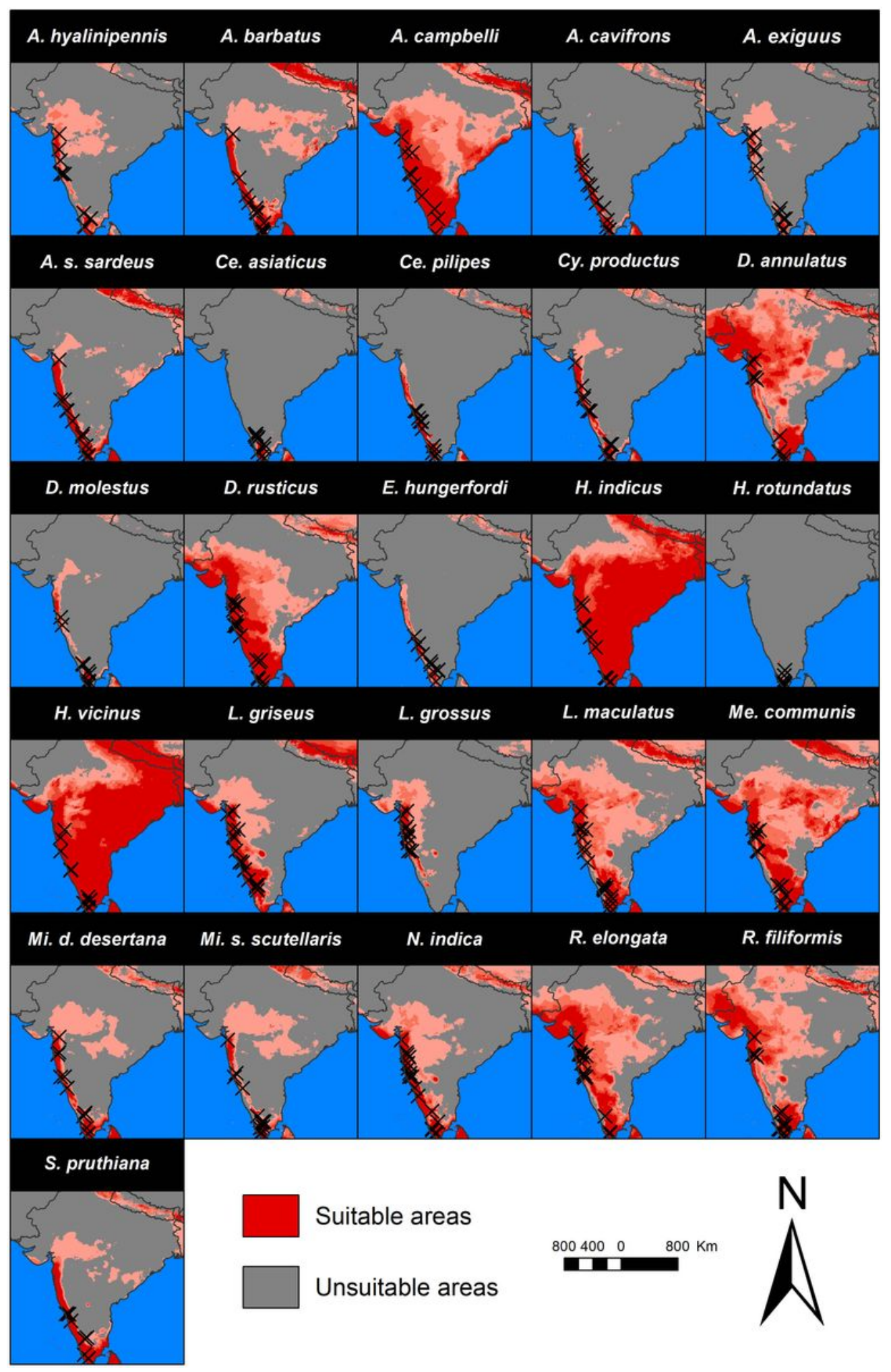

Figure 2

Future distributions of the 26 species of aquatic true bugs we modeled in this study. 


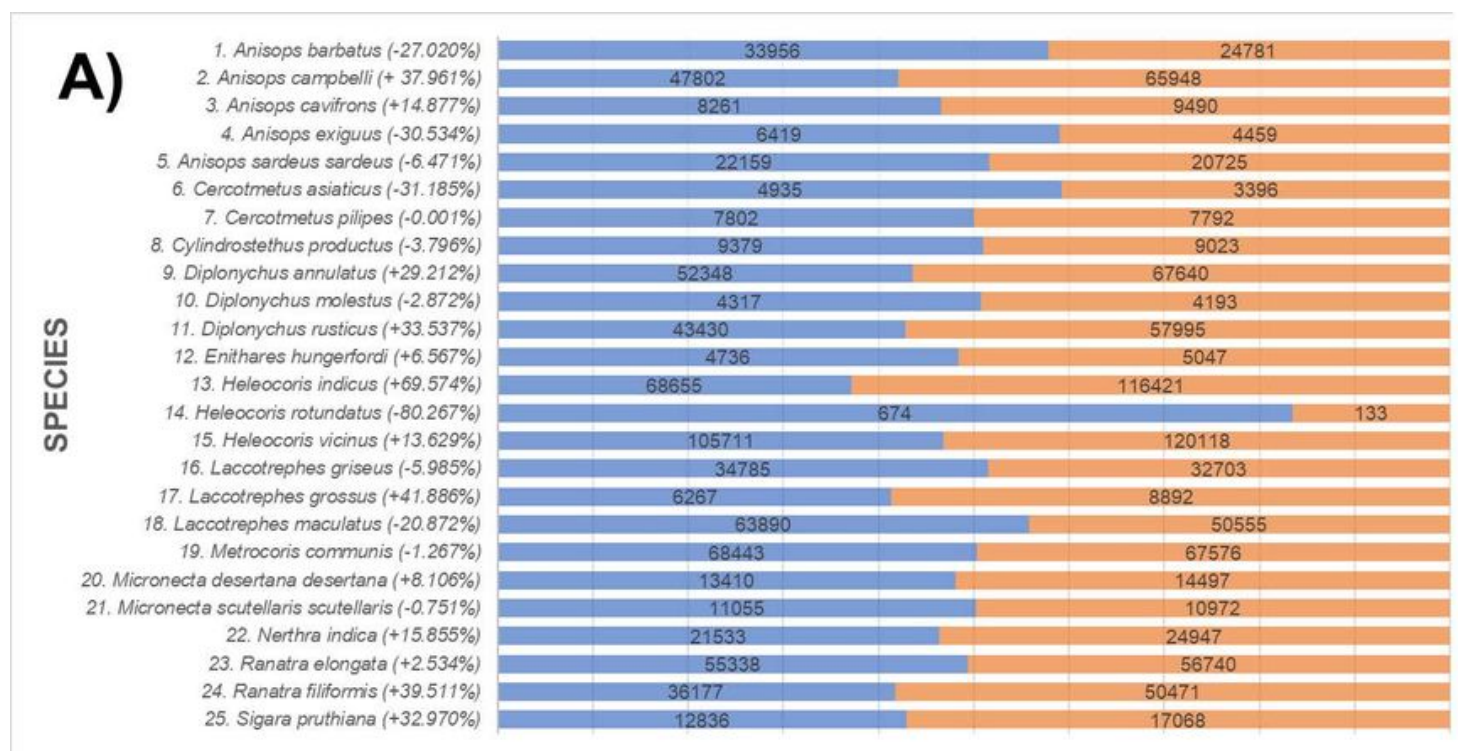

RANGE SIZE DIFFERENCE

B) $\quad$ Current Scenario $=$ Future Scenario

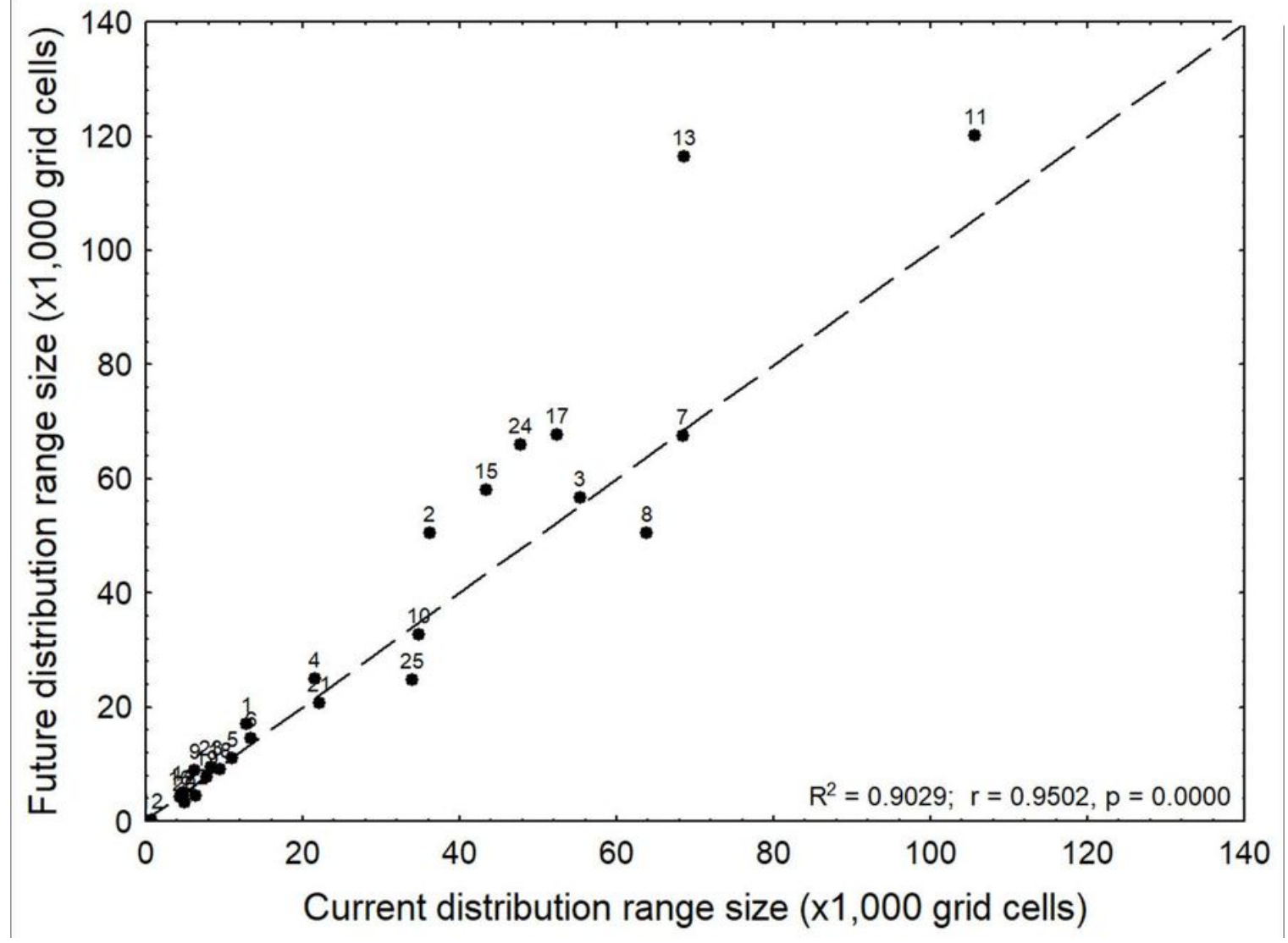

Figure 3

Distribution range sizes of the 26 species of aquatic true bugs in both current and future scenarios, considering $A$ ) the absolute size of each species in both scenarios and $B$ ) the species range size in relation to the other ones. The dashed line in $B$ corresponds to the scenario where both current and future distribution range of the species would not change. The case numbers showed in B (1 to 25 ) correspond to the species showed in A. 

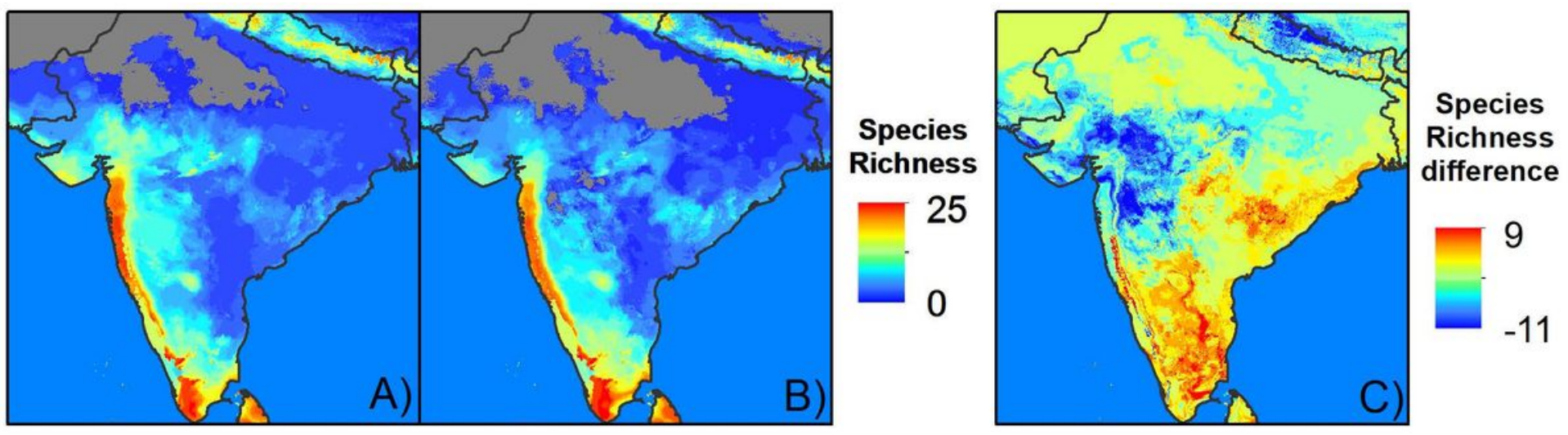

Figure 4

- Modeled species richness of the aquatic true bug species evaluated in this study considering both A) current scenario, B) future scenario and C) the difference in species richness between the scenarios. 